\title{
Prognostic evaluation based on a new TNM staging system proposed by the International Association for the Study of Lung Cancer for resected non-small cell lung cancers
}

Takayuki Fukui, MD, Shoichi Mori, MD, Shunzo Hatooka, MD, Masayuki Shinoda, MD, and Tetsuya Mitsudomi, MD

From the Department of Thoracic Surgery, Aichi Cancer Center Hospital, Nagoya, Japan.

Received for publication Sept 21, 2007; revisions received Dec 4, 2007; accepted for publication Dec 18, 2007.

Address for reprints: Takayuki Fukui, MD, Department of Thoracic Surgery, Aichi Cancer Center Hospital, 1-1 Kanokoden, Chikusa-Ku, Nagoya 464-0021, Japan (E-mail: tfukui@aichi-cc.jp).

J Thorac Cardiovasc Surg 2008;136:1343-8 0022-5223/\$34.00

Copyright $\odot 2008$ by The American Association for Thoracic Surgery

doi:10.1016/j.jtcvs.2007.12.085
Objective: The TNM classification has been widely used as a guide for estimating prognosis and is the basis for treatment decisions on various solid tumors. The International Association for the Study of Lung Cancer Staging Committee has proposed a new staging system for the next revision scheduled in 2009. However, its validity has not been established fully. Here we assessed its utilities and drawbacks.

Methods: We reviewed 1556 consecutive patients with non-small cell lung cancers who underwent pulmonary resection in our institution and reviewed their survival characteristics based on the 2009 system compared with the current (1997) system.

Results: The numbers of patients with stage IIA disease increased remarkably when using the 2009 system because of the reclassification of stages IB and IIB. Although the 5-year survival rates of the patients with stage IB and IIA disease in the 1997 system showed no difference with the 2009 system, the survival rates of patients with stage IB disease was $68.0 \%$, which is better than that of patients with stage IIA disease $(57.6 \%)$. The patient survival curves showed stepwise deterioration as the numbers increased, except for patient with stage IV disease.

Conclusions: Our study supported the proposal for this new staging system. Compared with the 1997 system, the 2009 system appears to be superior in separating stage IB and IIA disease and provides an even distribution among the stage groupings, although it is slightly complicated. The survival characteristics of 1556 resected cases in this single Japanese institution validated the proposed 2009 system.

$\mathrm{T}$ The TNM classification of cancers proposed by the Union Internationale Contre le Cancer has been widely accepted as a guide for estimating patient prognosis and is the basis for treatment decisions in practice. In lung cancer the first edition of the TNM classification was published in 1968, and it has been revised 5 times: in 1974 (second edition), 1978 (third edition), 1987 (fourth edition), 1997 (fifth edition), and 2002 (sixth edition). The 1997 revision has undergone an extensive correction for many deficiencies in the old staging system. ${ }^{1}$ The sixth and current edition from 2002 is a minor revision of the fifth edition, and the next revision is scheduled in 2009.

Thus the staging system has been revised many times to make it better. However, there are still some controversies and proposals for revision in the current edition. In a large-scale retrospective study of non-small cell lung cancer (NSCLC) performed by the Japanese Joint Committee of Lung Cancer Registry, no difference in prognosis between stage IB and IIA disease was seen in either clinical or pathologic settings. ${ }^{2}$ Many investigators reported similar discordant results concerning stage IB and IIA disease. ${ }^{3-6}$ In addition, although a satellite tumor nodule in the primary lobe is defined as T4 in the current system, some suggested that it might behave more favorably than in patients with another subgroup of $\mathrm{T} 4 .^{7}$ As a result, distinguishing the prognoses of 


\section{Abbreviations and Acronyms}

BAC = bronchioloalveolar carcinoma

IASLC = International Association for the Study of Lung Cancer

patients with stage IIIA and IIIB disease is sometimes unclear. $^{5,8,9}$ To correct these controversies, the International Association for the Study of Lung Cancer (IASLC) Staging Committee proposed a new staging system for the next revision (summarized in Table 1 and Figure 1). ${ }^{10-13}$

The purpose of this retrospective study was to review the survival characteristics of patients based on the new staging system proposed by the IASLC. We studied 1556 consecutive patients who underwent pulmonary resection in a single institution, Aichi Cancer Center Hospital. We also discuss the utilities and drawbacks of the new staging system.

\section{Materials and Methods Patient Cohort}

Approval for this study was obtained from and the need for individual patient consent was waived by the institutional review board. During a 21-year period from 1982 through 2002, 1556 patients with primary NSCLCs were enrolled in this study. The patients with pathologic stage IA to IV disease, including clinical patients with $\mathrm{N} 2$ disease, underwent surgical intervention. All patients underwent surgical resection with nodal dissection at the Aichi Cancer Center Hospital and were followed up for at least 5 years or until death. Data extracted from each patient's medical record included age, sex, smoking history, tumor histology and location, adjuvant and induction therapies, date of last follow-up, and death from any cause. The median follow-up period was 104 months. The patients comprised 1021 (66\%) men and 535 (34\%) women, ranging in age from 24 to 89 years (mean \pm standard deviation, $62 \pm 9.8$ years). There were 977 (63\%) adenocarcinomas, 429 (28\%) squamous cell carcinomas, 87 (5\%) large cell carcinomas, and $63(4 \%)$ other types of cancers. Evaluation of $\mathrm{pN}$ classification was determined from pathologic examination of resected specimens, including determination of the location and number of lymph nodes examined and the number found to be positive.

Preoperative therapy was performed in $52(3 \%)$ patients. They comprised 16 patients with clinical stage IIB, 25 with stage IIIA, 8 with stage IIIB, and 2 with stage IV disease. Among them, 27 and 8 patients underwent chemotherapy or radiotherapy, and 16 patients underwent chemoradiotherapy. Postoperative adjuvant chemotherapy was administered to only $10(0.6 \%)$ patients with stage IB or higher disease in this cohort.

\section{New Staging System}

Changes in the new TNM staging system for lung cancer proposed by the IASLC are listed in Table 1. Concerning the T descriptor, the IASLC proposed a subclassification of the current T2 tumors according to tumor size: those larger than $3 \mathrm{~cm}$ to $5 \mathrm{~cm}$ or less or classified as T2 based on another factor and $5 \mathrm{~cm}$ or less are defined as $\mathrm{T} 2 \mathrm{a}$, those larger than $5 \mathrm{~cm}$ to $7 \mathrm{~cm}$ or less are defined as T2b, and
TABLE 1. Summary of the proposal for changes to the sixth edition of the TNM classification ${ }^{10}$

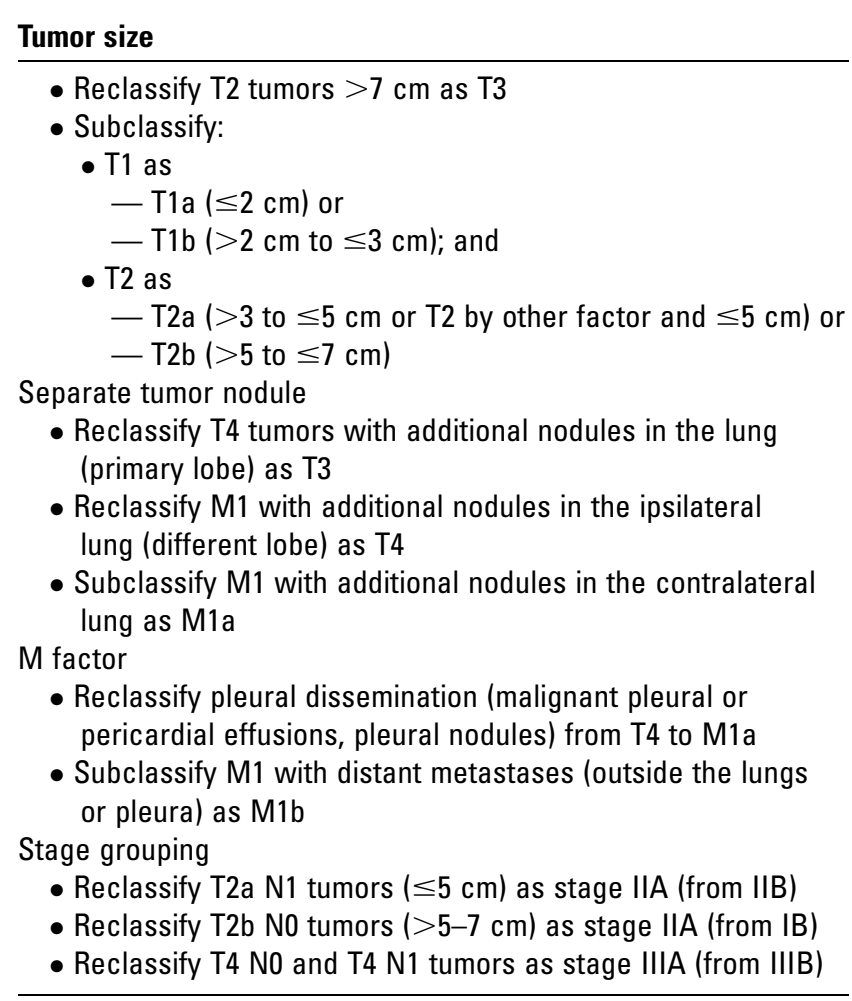

those larger than $7 \mathrm{~cm}$ are defined as T3. An additional tumor nodule in the same lobe is classified as T3 and in the ipsilateral different lobe as T4 but as M1a if it is in the contralateral lung. In addition, pleural dissemination is classified as M1a. Concerning the $\mathrm{N}$ classification, the IASLC supported the continued use of the current N0, $\mathrm{N} 1, \mathrm{~N} 2$, and N3 stage descriptors. ${ }^{12}$ In the stage grouping the IASLC proposed to reclassify T2a N1 (current IIB) and T2b NO (current IB) collectively as stage IIA disease and T4 N0 and T4 N1 (current IIIB) as stage IIIA disease.

\section{Survival Analyses}

The Kaplan-Meier method was used to plot the survival curves, and the log-rank test was used to evaluate differences between subgroups. To evaluate the significance of the new classification as an independent prognostic factor, we performed multivariate analysis by using the Cox proportional hazards model with 2 different

\begin{tabular}{|c|c|c|c|c|c|}
\hline & T1a, T1b & T2a & T2b & T3 & T4 \\
\hline N0 & IA & IB & IIA & IIB & IIAA \\
\hline N1 & IIA & IIA & IIB & IIIA & IIIA \\
\hline N2 & IIIA & IIIA & IIIA & IIIA & IIIB \\
\hline N3 & IIIB & IIIB & IIIB & IIIB & IIIB \\
\hline
\end{tabular}

Figure 1. The stage grouping according to the proposed system by the IASLC. ${ }^{10}$ 
models: one that included the current staging system (the 1997 system) and the other being the proposed one (the 2009 system). Trend $P$ values were assessed by using score tests. Statistical calculations were performed with a statistical package (StatView version 5.0; SAS Institute, Inc, Cary, NC).

\section{Results}

\section{Distribution of Pathologic Stage}

According to the 1997 system, patients were distributed as follows: stage IA, $n=448$ (28.8\%); stage IB, $n=368$ (23.7\%); stage IIA, $\mathrm{n}=44(2.8 \%)$; stage IIB, $\mathrm{n}=194(12.5 \%)$; stage IIIA, $\mathrm{n}=317(20.4 \%)$; stage IIIB, $\mathrm{n}=122(7.8 \%)$; and stage $\mathrm{IV}, \mathrm{n}=63(4.0 \%)$. When applied to the 2009 system, they were distributed as follows: stage IA, $\mathrm{n}=448(28.8 \%)$; stage $\mathrm{IB}, \mathrm{n}=278(17.9 \%)$; stage IIA, $\mathrm{n}=175(11.2 \%)$; stage IIB, $\mathrm{n}=155(10.0 \%)$; stage IIIA, $\mathrm{n}=378(24.3 \%)$; stage IIIB, $\mathrm{n}=41(2.6 \%)$; and stage IV, $\mathrm{n}=81$ (5.2\%; Figure 2). Comparing the 2 distributions, the proportion of patients with stage IIA disease was increased remarkably by the reclassification of patients with stage IB and IIB disease. Sixty patients with current stage IB disease were redefined as having new stage T2b N0 M0 disease, and 71 patients with current stage IIB disease were redefined as having new stage T2a N1 M0 disease and shifted to a new stage, IIA. One hundred thirty-seven patients were shifted to a higher stage with the 2009 system, mostly from IB to IIA $(n=60)$. On the other hand, 139 patients were shifted to a lower stage, and most of these were from stages IIB to IIA (Table 2).

\section{Survival Analysis}

Survival curves and the 5-year survival rates according to the 1997 and 2009 staging systems are shown in Figure 3. The

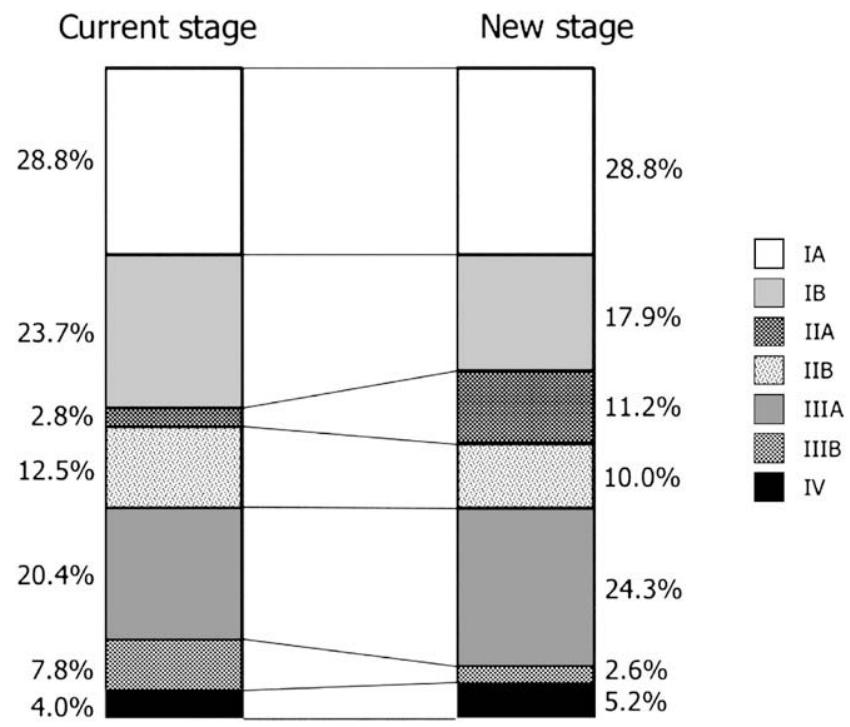

Figure 2. Distribution of the patients according to the current and proposed new stage groupings. The proportion of patients with stage IIA disease increased remarkably because they were reclassified from current stages IB and IIB.
TABLE 2. Comparison between current and proposed pathologic stages

\begin{tabular}{lrrrrrrrr}
\hline & \multicolumn{8}{c}{ 2009 system } \\
\cline { 2 - 9 } 1997 system & IA & IB & IIA & IIB & IIIA & IIIB & IV & Total \\
\hline IA & 448 & 0 & 0 & 0 & 0 & 0 & 0 & 448 \\
IB & 0 & 278 & 60 & 30 & 0 & 0 & 0 & 368 \\
IIA & 0 & 0 & 44 & 0 & 0 & 0 & 0 & 44 \\
IIB & 0 & 0 & 71 & $\mathbf{1 1 4}$ & 10 & 0 & 0 & 195 \\
IIIA & 0 & 0 & 0 & 0 & $\mathbf{3 1 6}$ & 0 & 0 & 316 \\
IIIB & 0 & 0 & 0 & 11 & 38 & $\mathbf{3 6}$ & 37 & 122 \\
IV & 0 & 0 & 0 & 0 & 14 & 5 & $\mathbf{4 4}$ & 63 \\
Total & 448 & 278 & 175 & 155 & 378 & 41 & 81 & 1556 \\
\hline
\end{tabular}

5 -year survival rates of the patients with current stage IB and IIA disease were $64.9 \%$ and $65.9 \%$, respectively, in this cohort, being almost identical $(P=.54)$. With respect to the 2009 system, the survival curves showed stepwise deterioration as the stage increased, except for patients classed as having stage IV disease. The 5-year survival rate of patients classed as having stage IB disease was $68.0 \%$, which was better than that of those with stage IIA disease $(57.6 \%$; $P=.09$; Figure $3, B)$. We analyzed the patient survival
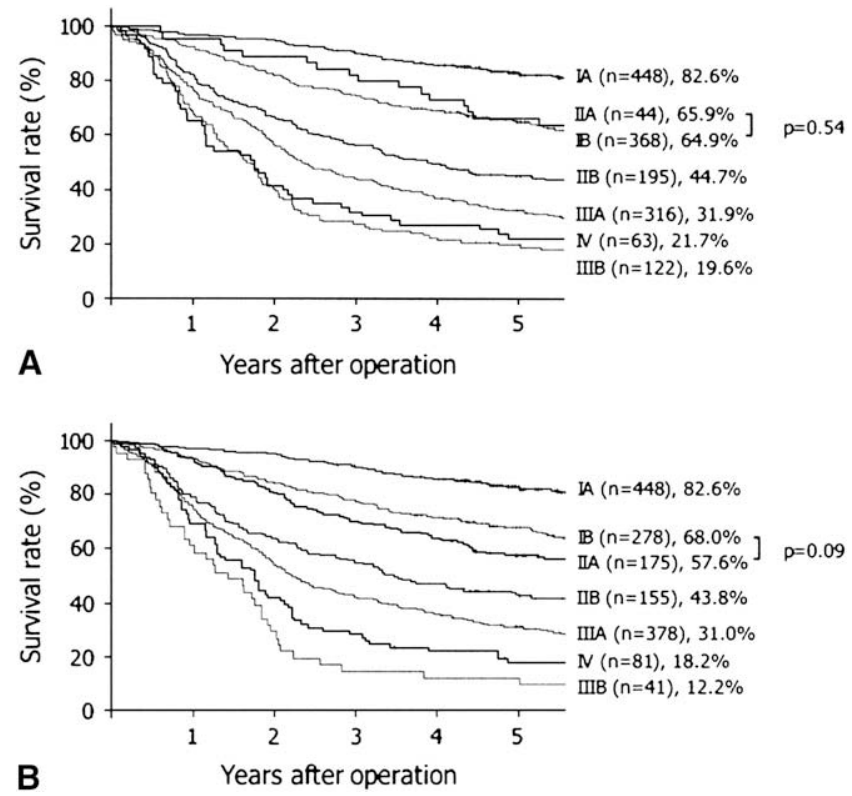

Figure 3. Survival curves for patient subgroups stratified according to stage groupings. The 5-year survival rate and the number of patients in each subgroup are indicated. A, With regard to the current staging system, no survival difference was observed between patients with stage IB and IIA disease $(P=.54)$. B, With regard to the proposed system, the survival curves showed significant stepwise deterioration as the numbers increased, except for patients with stage IV tumors. There was a difference in the prognoses of patients with stage IB and IIA disease, although this was not statistically significant $(P=.09)$. 

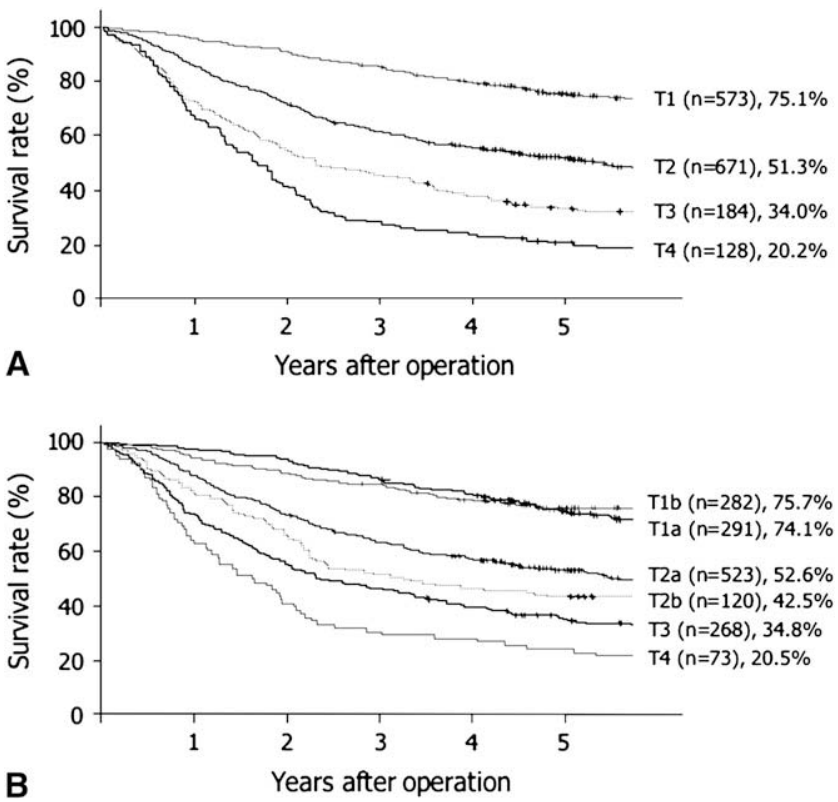

Figure 4. Survival curves for patient subgroups stratified according to $T$ descriptors. The 5-year survival rate and the number of patients in each subgroup are indicated. A, With regard to the current staging system, the survival curves showed significant stepwise deterioration as the numbers increased. B, For the proposed system, there was no significant prognostic difference between the new T1a and T1b stages $(P=.35)$.

characteristics for the $\mathrm{T}$ descriptors and found no prognostic difference between T1a and T1b tumors $(P=.35$, Figure 4$)$. Concerning satellite tumor nodules, 22 patients who were classified as having T4 tumors only because of their satellite tumor nodules showed significantly better survival than that of other patients with T4 tumors. The 5-year survival rate of these 22 patients was $36 \%$, whereas it was $17 \%$ in the other T4 group $(P=.038)$.

Multivariate analysis with the Cox proportional hazard model was performed to evaluate the significance of the stage groupings, including the following variables: age, sex, histology, and 1997 and 2009 stage grouping. Each stage grouping was tested independently in the same combination with other variables. The result is summarized in Table 3. Hazard ratios for stage IB and IIA disease in the 1997 system referred to as stage IA disease were 1.83 and 1.80 , respectively, versus 1.72 and 2.17 in the 2009 system. Among the clinicopathologic variables analyzed, each stage grouping was an independent prognostic factor.

\section{Discussion}

The staging system for cancer according to TNM classification is an accepted principle used by oncologists. It serves many objectives: to give some indication of prognosis, to plan treatments, to evaluate the results of treatments, to
TABLE 3. Comparison of hazard ratios by means of 2 multivariate analyses with the Cox hazard model

\begin{tabular}{lccccc}
\hline & \multicolumn{2}{c}{ 1997 staging system } & & \multicolumn{2}{c}{ 2009 staging system } \\
\cline { 2 - 3 } \cline { 5 - 6 } & Hazard ratio & $\mathbf{9 5 \%} \mathbf{~ C l}$ & & Hazard ratio & $\mathbf{9 5 \%} \mathbf{~ C l}$ \\
\hline IA & 1.00 & & & 1.00 & \\
IB & 1.83 & $1.46-2.30$ & & 1.72 & $1.35-2.20$ \\
IIA & 1.80 & $1.13-2.85$ & & 2.17 & $1.67-2.83$ \\
IIB & 3.11 & $2.42-3.99$ & & 3.16 & $2.43-4.11$ \\
IIIA & 4.68 & $3.77-5.81$ & & 4.96 & $4.02-6.12$ \\
IIIB & 7.34 & $5.64-9.55$ & & 10.60 & $7.35-15.4$ \\
IV & 6.50 & $4.66-9.07$ & & 7.35 & $5.46-9.89$ \\
& Trend $P<.0001$ & & Trend $P<.0001$ &
\end{tabular}

Each stage grouping was tested independently in the same combination with other variables. Other variables are as follows: age $(<62 / \geq 62$ years), sex (male/female), and histology (squamous/nonsquamous). $\mathrm{Cl}$, Confidence interval.

facilitate the exchange of information among institutions, and to contribute to the continuing investigation of human cancer. ${ }^{14,15}$ Therefore the system should be revised according to the prognosis of patients with relatively homogeneous backgrounds. For lung cancers, the American Joint Committee on Cancer and Union Internationale Contre le Cancer adopted several revisions to the 1986 stage classification, changes that were later published by Mountain ${ }^{1}$ in 1997 as the fifth edition. For the next revision scheduled in 2009, the IASLC Staging Committee has proposed a new staging system based on a well-organized, large international database covering more than 80,000 patients with lung cancers. ${ }^{10-13}$ In the present study we attempted to assess the validity of the proposed revision.

One of the most important aims for the next revision is to correct the similar survival rates of patients with stage IB and IIA disease, which is partly caused by the relatively few patients with stage IIA disease, as reported by many investigators: $1.4 \%$ in Mountain's series, ${ }^{1} 3.5 \%$ in the Japanese series, ${ }^{2} 3.7 \%$ in the series by Naruke and colleagues, ${ }^{6}$ and $4.4 \%$ in the series by Inoue and associates. ${ }^{3}$ Mountain had already reported the similar prognoses for patients with stage IB and IIA disease: $57 \%$ and 55\%, respectively. ${ }^{1}$ In our cohort no survival difference was observed between patients with stage IB or IIA disease (64.9\% and 65.9\%, respectively), and patients with stage IIA disease accounted for only $2.8 \%$ of the whole. According to this proposal, the number of patients categorized as having stage IIA disease increased to $175(11 \%)$ from $44(2.8 \%)$ in our cohort. The survival analysis showed differences between the prognoses of patients with stage IB and IIA disease, although the difference was not statistically significant $(P=.09)$.

Other overlapping prognoses of patients with neighboring stages were seen between stages IIIB and IV in this study. In the 2009 system an additional tumor nodule in the same lobe is classified as T3 and pleural dissemination 
as M1. Therefore the patients with stage IIIB disease decreased from $122(7.8 \%)$ to $41(2.6 \%)$. The worse 5-year survival rates than seen with current stage IIIB disease (12.2\% and $19.6 \%$ ) seem to be because of the shifting of patients who behaved more favorably than other subgroups of patients with T4 tumors to the earlier stages. Because this retrospective study only included resected cases and most patients with advanced stages are generally not candidates for surgical intervention, the patients with stage III and IV disease in this study did not represent the whole population of these stage groups.

In the 1997 TNM classification, a satellite tumor nodule in the primary lobe is defined as T4. However, some investigators suggested that patients with a satellite tumor nodule in the primary lobe might behave more favorably than patients with other subgroups of T4 tumors. ${ }^{7,16}$ Because 22 patients with satellite tumor nodules in the same lobe showed significantly better survival than the other patients with T4 tumors in this study, the 2009 system seems to be appropriate. Usually, any satellite tumor nodule in a different lobe is regarded as metastatic, but it remains arguable whether the nodule is really a metastatic lesion or a synchronous lung neoplasm. However, it is very difficult to distinguish them by means of preoperative evaluations with imaging studies in clinical practice.

Many investigators have reported the effects of tumor size on stage, curability, and patient survival. ${ }^{9,17-19}$ In the 2009 system current T1 tumors should be divided into T1a (tumors $\leq 2 \mathrm{~cm}$ in greatest dimension) and $\mathrm{T} 1 \mathrm{~b}$ (tumors $>2 \mathrm{~cm}$ but $\leq 3 \mathrm{~cm}$ ) tumors, although the subclassification would not be reflected in stage grouping. ${ }^{10,11}$ In this study we analyzed the survival characteristics according to the $\mathrm{T}$ descriptors and found no prognostic difference between the new $\mathrm{T} 1 \mathrm{a}$ and $\mathrm{T} 1 \mathrm{~b}$ classifications (Figure 3 ). One possible reason might be the limited value of the evaluation of invasiveness by tumor size alone. Recent clinical use of high-resolution computed tomographic analysis has greatly advanced the diagnosis of small lesions of the peripheral lung. Bronchioloalveolar carcinoma (BAC), which is detected as such a small lesion, is the noninvasive form of an adenocarcinoma and often included in the smaller $\mathrm{T}$ category. In the revised World Health Organization histologic classification, a BAC is classified as a noninvasive carcinoma with no evidence of stromal, vascular, or pleural invasion. The excellent prognosis for patients after surgical resection of BACs is already well recognized. ${ }^{20}$ In the present study the histologic category as an adenocarcinoma might have included a BAC, and its prognostic significance was not demonstrated independently. Asamura and coworkers ${ }^{21}$ suggested that these noninvasive BACs should be newly termed as Ti and excluded from the T1 category. On the other hand, hilar or mediastinal nodal metastases have been found even in patients with adenocarcinomas of $1.0 \mathrm{~cm}$ or less. ${ }^{22,23}$ Moreover, in our cohort lymph node involvement had been found in 3 patients among 18 adenocarcinomas measuring $1 \mathrm{~cm}$ or less in diameter (detailed data not shown). Thus tumor size alone cannot be an indicator of the invasive nature of the small lung adenocarcinomas. $^{24}$

On the other hand, subclassification by tumor size might have an effect on postoperative adjuvant therapy. The standard of care for resected stage II to IIIA NSCLC now includes adjuvant chemotherapy based on the results of 3 phase III studies using cisplatin-based regimens. ${ }^{25-27}$ However, the role of adjuvant chemotherapy for stage I disease remains controversial. Updated results from the Cancer and Leukemia Group B 9633 trial, the only trial to focus exclusively on patients with stage IB disease, no longer shows a statistically significant survival benefit from adjuvant chemotherapy in this population. ${ }^{28}$ The patient who would take a survival benefit might be found by the subclassification of current $\mathrm{T} 1$ and T2 tumors in the 2009 system.

Concerning the $\mathrm{N}$ classification, the survival rates decreased as the $\mathrm{N}$ number progressed, whereas prognostic significance was found between $\mathrm{N}$ classes in our cohort (Figure 5). We reported previously that the number of positive lymph nodes was a strong independent prognostic factor in patients with resected NSCLCs and could stratify the patients with N2 disease into a homogenous subgroup. ${ }^{29}$ We hope that consideration will be given to its inclusion in pathologic staging in the future. Regarding the lymph node map showing the sites of nodes, the Japan Lung Cancer Society has produced the Naruke map, ${ }^{30}$ which is based on bronchial trees, thoracotomy findings, and resected specimens, and there is also a map based on the Mountain-Dresler modification of the map from the American Thoracic Society, ${ }^{31}$ which is based on mediastinal pleura and mediastinoscopic identification. The 2 maps have different views on the definition between levels 7 and 10 , which causes confusion in the definitions of N1 and N2. Although the proposal by the IASLC included the "zone" concept, which groups lymph nodes from several nodal stations, and suggested that this concept also reconciled the slight differences in nomenclature between the 2 maps, ${ }^{12}$ discussion on the issue is still underway.

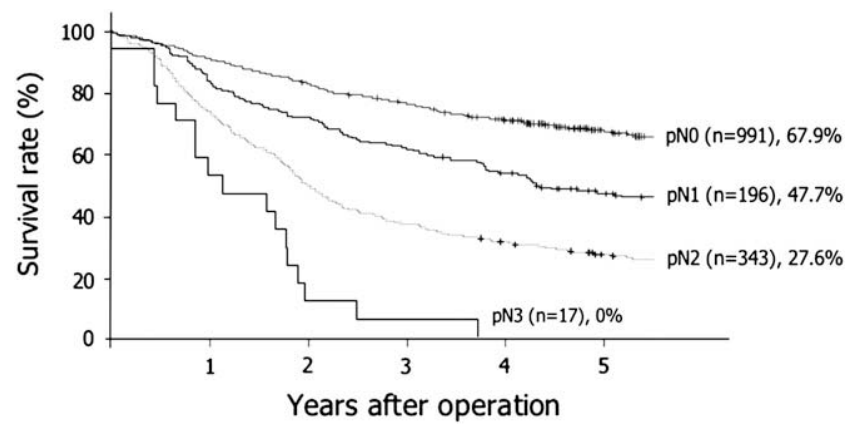

Figure 5. Survival curves for patient subgroups stratified according to $\mathbf{N}$ descriptors. The survival curves showed significant stepwise deterioration as the numbers increased. 
Our study supports the proposals for the new TNM staging system of lung cancer as reported by the IASLC Staging Committee. Our survival characteristics of 1556 patients with resected NSCLCs in a single Japanese institution validated this proposed staging system, which is based on a large international database, particularly among patients with pathologic stage IA to IIIA disease. In this study patients with stage IIIB disease showed a worse survival rate than those with stage IV disease. Because this retrospective study only included resected cases, the patients with stages III and IV disease did not represent the whole population of these stage groups. In any case we should always prepare for future modifications of the TNM staging system as we gain more knowledge about the biology of lung cancer. Last, we hope to make the revised staging system easier to remember and less cumbersome for clinicians involved in the management of lung cancer.

We thank Dr Keitaro Matsuo, Division of Epidemiology and Prevention, Aichi Cancer Center Research Institute, for his advice on statistical analyses.

\section{References}

1. Mountain CF. Revisions in the International System for Staging Lung Cancer. Chest. 1997;111:1710-7.

2. Goya T, Asamura H, Yoshimura H, Kato H, Shimokata K, Tsuchiya R, et al. Prognosis of 6644 resected non-small cell lung cancers in Japan: a Japanese lung cancer registry study. Lung Cancer. 2005;50:227-34.

3. Inoue K, Sato M, Fujimura S, Sakurada A, Takahashi S, Usuda K, et al. Prognostic assessment of 1310 patients with non-small-cell lung cancer who underwent complete resection from 1980 to 1993. J Thorac Cardiovasc Surg. 1998;116:407-11.

4. Jassem J, Skokowski J, Dziadziuszko R, Jassem E, Szymanowska A, Rzyman W, et al. Results of surgical treatment of non-small cell lung cancer: validation of the new postoperative pathologic TNM classification. J Thorac Cardiovasc Surg. 2000;119:1141-6.

5. Adebonojo SA, Bowser AN, Moritz DM, Corcoran PC. Impact of revised stage classification of lung cancer on survival: a military experience. Chest. 1999;115:1507-13.

6. Naruke T, Tsuchiya R, Kondo H, Asamura H. Prognosis and survival after resection for bronchogenic carcinoma based on the 1997 TNM-staging classification: the Japanese experience. Ann Thorac Surg. 2001;71:1759-64.

7. Urschel JD, Urschel DM, Anderson TM, Antkowiak JG, Takita H. Prognostic implications of pulmonary satellite nodules: are the 1997 staging revisions appropriate? Lung Cancer. 1998;21:83-7; discussion 89-91.

8. Kameyama K, Huang CL, Liu D, Okamoto T, Hayashi E, Yamamoto Y, et al. Problems related to TNM staging: patients with stage III non-small cell lung cancer. J Thorac Cardiovasc Surg. 2002;124:503-10.

9. Koike T, Terashima M, Takizawa T, Aoki T, Watanabe T, Akamatsu H. Results of surgery for primary lung cancer based on the new international staging system. Jpn J Thorac Cardiovasc Surg. 1999;47:313-7.

10. Goldstraw P, Crowley J, Chansky K, Giroux DJ, Groome PA, RamiPorta R, et al. The IASLC Lung Cancer Staging Project: proposals for the revision of the TNM stage groupings in the forthcoming (seventh) edition of the TNM classification of malignant tumours. J Thorac Oncol. 2007;2:706-14.

11. Rami-Porta R, Ball D, Crowley J, Giroux DJ, Jett J, Travis WD, et al. The IASLC Lung Cancer Staging Project: proposals for the revision of the T descriptors in the forthcoming (seventh) edition of the TNM classification for lung cancer. J Thorac Oncol. 2007;2:593-602.
12. Rusch VW, Crowley J, Giroux DJ, Goldstraw P, Im JG, Tsuboi M, et al. The IASLC Lung Cancer Staging Project: proposals for the revision of the $\mathrm{N}$ descriptors in the forthcoming seventh edition of the TNM classification for lung cancer. $J$ Thorac Oncol. 2007;2:603-12.

13. Postmus PE, Brambilla E, Chansky K, Crowley J, Goldstraw P, Patz EF Jr, et al. The IASLC Lung Cancer Staging Project: proposals for revision of the $\mathrm{M}$ descriptors in the forthcoming (seventh) edition of the TNM classification of lung cancer. J Thorac Oncol. 2007;2: 686-93.

14. Union Internationale Contre le Cancer. TNM classification of malignant tumours. 5th ed. Geneva: Union Internationale Contre le Cancer; 1997.

15. Union Internationale Contre le Cancer. TNM classification of malignant tumours. 6th ed. Geneva: Union Internationale Contre le Cancer; 2002.

16. Yano $M$, Arai $T$, Inagaki $K$, Morita $T$, Nomura $T$, Ito H. Intrapulmonary satellite nodule of lung cancer as a T factor. Chest. 1998;114:1305-8.

17. Heyneman LE, Herndon JE, Goodman PC, Patz EF Jr. Stage distribution in patients with a small $(<$ or $=3 \mathrm{~cm})$ primary nonsmall cell lung carcinoma. Implication for lung carcinoma screening. Cancer. 2001;92: 3051-5.

18. Gajra A, Newman N, Gamble GP, Abraham NZ, Kohman LJ, Graziano SL. Impact of tumor size on survival in stage IA non-small cell lung cancer: a case for subdividing stage IA disease. Lung Cancer. 2003;42:51-7.

19. Wisnivesky JP, Yankelevitz D, Henschke CI. The effect of tumor size on curability of stage I non-small cell lung cancers. Chest. 2004;126:761-5.

20. Noguchi M, Morikawa A, Kawasaki M, Matsuno Y, Yamada T, Hirohashi S, et al. Small adenocarcinoma of the lung. Histologic characteristics and prognosis. Cancer. 1995;75:2844-52.

21. Asamura H, Goya T, Koshiishi Y, Sohara Y, Tsuchiya R, Miyaoka E. How should the TNM staging system for lung cancer be revised? A simulation based on the Japanese Lung Cancer Registry populations. $J$ Thorac Cardiovasc Surg. 2006;132:316-9.

22. Asamura H, Suzuki K, Watanabe S, Matsuno Y, Maeshima A, Tsuchiya R. A clinicopathological study of resected subcentimeter lung cancers: a favorable prognosis for ground glass opacity lesions. Ann Thorac Surg. 2003;76:1016-22.

23. Miller DL, Rowland CM, Deschamps C, Allen MS, Trastek VF, Pairolero PC. Surgical treatment of non-small cell lung cancer $1 \mathrm{~cm}$ or less in diameter. Ann Thorac Surg. 2002;73:1545-51.

24. Fukui T, Sakakura N, Mori S, Hatooka S, Shinoda M, Yatabe Y, et al. Controversy about small peripheral lung adenocarcinomas: how should we manage them? J Thorac Oncol. 2007;2:546-52.

25. Arriagada R, Bergman B, Dunant A, Le Chevalier T, Pignon JP, Vansteenkiste J, et al. Cisplatin-based adjuvant chemotherapy in patients with completely resected non-small-cell lung cancer. $N$ Engl J Med. 2004;350:351-60.

26. Winton T, Livingston R, Johnson D, Rigas J, Johnston M, Butts C, et al. Vinorelbine plus cisplatin vs. observation in resected non-small-cell lung cancer. N Engl J Med. 2005;352:2589-97.

27. Douillard JY, Rosell R, Delena M, Legroumellec A, Torres A, Carpagnano F. ANITA: phase III adjuvant vinorelbine (N) and cisplatin (P) versus observation (OBS) in completely resected (stage I-III) non-small-cell lung cancer (NSCLC) patients (pts): final results after 70-month median follow-up. On behalf of the Adjuvant Navelbine International Trialist Association. J Clin Oncol. 2005;23:624s.

28. Strauss GM, Herndon JE, Maddaus MA, Johnston DW, Johnson EA, Watson DM. Adjuvant chemotherapy in stage IB non-small cell lung cancer (NSCLC): update on Cancer and Leukemia Group B (CALGB) protocol 9633. J Clin Oncol. 2006;24:365s.

29. Fukui T, Mori S, Yokoi K, Mitsudomi T. Significance of the number of positive lymph nodes in resected non-small cell lung cancer. $J$ Thorac Oncol. 2006; 1:120-5.

30. Naruke T, Suemasu K, Ishikawa S. Lymph node mapping and curability at various levels of metastasis in resected lung cancer. J Thorac Cardiovasc Surg. 1978;76:832-9.

31. Mountain CF, Dresler CM. Regional lymph node classification for lung cancer staging. Chest. 1997;111:1718-23. 